\title{
The rheology of three-phase lavas and magmas
}

\author{
EINAT LEV ${ }^{1 *}$, JANINE BIRNBAUM ${ }^{1}$, COLTON CONROY ${ }^{1}$, \\ AlAN WhitTINGTON ${ }^{2}$, BRENNA HALVERSON ${ }^{2}$, JULIA \\ HAMMER $^{3}$, ED LLEWELLIN ${ }^{4}$ \\ ${ }^{1}$ Lamont-Doherty Earth Observatory, Columbia University \\ (*Correspondence: einatlev@ldeo.columbia.edu) \\ ${ }^{2}$ University of Texas at San Antonio \\ ${ }^{3}$ University of Hawai'i at Manoa \\ ${ }^{4}$ Durham University
}

Rheology exerts a leading order control on magmatic flow within and outside of volcanoes. Quantitative expressions to describe magma and lava rheology are an essential component of predictive flow models. The viscosity of lava can vary over orders of magnitude, even within a single flow, and is highly sensitive to the presence of solid particles and gas bubbles. In particular, the effect of bubbles on the rheology of two- and three-phase suspensions remains an outstanding challenge in volcano science. Here, we combine analogue experiments, field observations and numerical flow models to investigate a broad range of crystal and bubble contents that are relevant to natural magmatic systems, with a particular focus on the 2018 Kilauea eruption.

In the lab, we utilize a dam-break consistometer setup to determine the rheology of corn syrup suspensions bearing particles (up to $\sim 45 \%$ by volume) and bubbles (up to $\sim 75 \%$ volume fraction.) We use neutrally buoyant, angular particles, with a nearly monodisperse size population. Bubbles are added to the mixture through a chemical reaction between baking soda and citric acid, which can generate high volume fractions of gas bubbles with polydisperse size populations similar to those observed in natural samples. We track flow advance over time and invert for the bulk effective rheological parameters in a Herschel-Bulkley formulation using a Markov Chain Monte Carlo numerical simulation, which yields parameter and uncertainty estimates.

We examine the impact of our new formulation on forward models of lava flow emplacement and magma ascent in a conduit. Our calculations specifically target the Fissure 8 channelized lava flows of the 2018 Kilauea eruption. The Fissure 8 lavas erupted with a high $(>60 \%)$ volume fraction of bubbles and observable crystals, and a wealth of observations documents their deformation and flow. These flows thus present a natural laboratory test case for the new, three-phase rheology we develop through the analog lab experiments. 